\title{
The Influence of Gas Flare Particulates and Rainfall on the Corrosion of Galvanized Steel Roofs in the Niger Delta, Nigeria
}

\author{
Ajah Ekpeni Obia ${ }^{1}$, Hanson Effiong Okon ${ }^{1}$, Samuel Aji Ekum ${ }^{1}$, Eyo Effiom Eyo-Ita ${ }^{1}$, \\ Ekpang Ajah Ekpeni ${ }^{2}$
}

\author{
${ }^{1}$ Department of Architecture, Cross River University of Technology, Calabar, Nigeria; ${ }^{2}$ Department of Chemistry, Cross River Co- \\ llege of Education, Akamkpa, Nigeria. \\ E-mail: ajahekpeni@yahoo.com
}

Received August $3^{\text {rd }}, 2011$; revised September $9^{\text {th }}, 2011$; accepted October $18^{\text {th }}, 2011$.

\begin{abstract}
An experiment was conducted to determine the influence of air-borne particulates exuded from gas flare chambers and rainfall/rain water $\mathrm{pH}$ in the rusting of metallic building materials, particularly the galvanized iron roofing sheets, in the Niger Delta Region of Nigeria. Gas flaring and rain fall in this region are rated to be amongst the highest in the world. In this experiment, specimens of the metal (galvanized iron) were exposed in the atmosphere for one year, across four sites within the region. The monthly readings of concentrations of particulate matter (aerosol) and rainfall at the sites were recorded. Equally, the average $\mathrm{pH}$ values of the collected rainwater were determined and recorded correspondingly. Multiple linear regression, analysis of variance (ANOVA) and Pearson Product Moment Correlation statistical analyses were performed on the obtained data and the outcome indicated that, with an $R^{2}=0.678$, there was significant influence of industrial aerosol concentration, precipitation and $\mathrm{pH}$ on the degradation of galvanized iron roofing material in the region. It was also established that their individual influences were less than their joint impact, suggesting synergism. The ANOVA test further indicated that corrosion was severe in the industrial sites of Ibeno and Ebocha while Ekuri (the control station) recorded the least impact. This study recommends a discontinuation of gas flaring in the region while research on environmentally resilient, relatively cheap and sustainable alternative materials should be encouraged.
\end{abstract}

Keywords: Galvanized Iron, Gas Flares, Mass Loss, Pollutants, Rainfall

\section{Introduction}

Metallic corrosion is an inarguably intractable problem in the construction industry. Global cost of corrosion to the industry is astronomical; especially in the developed and emerging economies [1-3]. Yet modern construction can safely be said to be most promoted and sustained with metals. Such unique qualities as durability, tensile strength, malleability, amongst others, make metals enviable components of modern construction. Unfortunately, this high profile material has one major shortcoming, susceptibility to corrosion attack. There is the universal tendency for any metallic material to return to its natural stable state (through corrosion) and that is often not the state in which humans would prefer to use it [4,5]. This vulnerability is higher in some metals than others.

In the building industry, iron, steel, aluminum and zinc are common on account of low cost and availability. Often times, some measures are taken to protect these metals against wear. Iron is galvanized (covered with protective zinc coating) and used as roof coverings. The material (galvanized iron) finds high use in the developing world, particularly the high rainfall regions like Niger Delta Region of Nigeria, where it is largely used as roofing material. The advantages of this material over the other two main rivals in roof covering, aluminum and asbestos, for instance, are quite obvious hence, its unassailable demand by the low and medium income earners as well as property developers.

Atmospheric corrosion needs electrolytic medium to take place [5-9]. Therefore, the presence of moisture on the metallic surface is an obvious pre-condition for the metal to degrade. Some scholars suggest that extreme pre- 
cipitation is likely to have a less impact on corrosion than drizzle or dews [6]. If the argument were to hold, we would have shorter replacement intervals (lifespan) of galvanized iron roofing sheets in the savannah (middle belt) region of Nigeria than the high equatorial rainforest of the south. That situation is seen to be the reverse; there is a greater tendency to change roofs in the south, particularly the southeastern axis and Niger Delta where the rainfall regime is ranked amongst the highest on the Globe $[10,11]$.

Quite a lot of reasons have been adduced to explain this phenomenon in the Delta, ranging from pollutant concentration (natural and industrial) to decline in product quality. The first reason stems from the fact that the region is inundated with gas flare points (there are 123 flare points in the region with a daily output of 50,000 cubic metres of gas) and this is considered to be amongst the highest in the world [12]. It is also one of the wettest zones with the richest ecosystems on earth [13-15]. More so, the combustion in the chambers in Niger Delta is at best incomplete, leading to the release of large amount of particulates often noticed as visible orange plumes from the flare stacks [16]. Thus, it is necessary to examine the combined influence of these two factors. This study is therefore aimed at determining the influence of gaseous aerosols (particulates) and precipitation (rainfall) on the corrosion menace, especially the degradation of galvanized iron, the major roofing material in Nigeria.

\section{Materials and Methods}

\subsection{The Study Sites}

Four exposure sites were chosen across the region under study. Though the zone is noted for its high rainfall and intense flaring activities, the distribution of these events is not uniform. The four sites were chosen to capture as much of these variables as possible. The sites were at Qua Iboe Oil Terminal (QIT), Ibeno, in Akwa Ibom State, designated as " $\mathrm{M}$ " and National Agip Oil Company (NAOC), Ebocha in Rivers State, designated as "N". Others were at Ekuri, "O" and Ogoja, "P"; all in Cross River State of Nigeria. Ibeno is a coastal community by the bank of Atlantic Ocean and with oil facilities. Ebocha is about $100 \mathrm{~km}$ away from the sea and is an industrial zone with oil facilities as well. Ekuri is a village situated deep inside the dense Cross River rainforest, at the foot of Oban hill, and free from any form of industrial activity. This rolling high land is an extension of the Cameroon massif that is noted for its high relief rainfalls. Ekuri is thus chosen as a control station in this study on account of its being free from industrial activities. Ogoja is an urban area with savannah vegetation and comparatively less rainfall. It is an administrative headquarters with no industries. Table 1 shows a brief descriptive classification of the sites based on pollution and environmental factors while Figure 1 shows the map of Niger Delta region with the study sites. The average temperature of the region oscillates around $30^{\circ} \mathrm{C}$ except at Ogoja where average temperature is $32^{\circ} \mathrm{C}$. The relative humidity in the region is in the range of $80 \%-90 \%$ all year round.

\subsection{Materials}

The basic materials and equipment used for the experiment included the local commercial brand of corrugated galvanized iron roofing sheets (zinc), a wooden rack and plastic strings. Others included automatic high precision air quality monitoring station (manufactured by ELE International of England) attached with climatic and pollutant sensors, a sensitive analytical electronic weighing balance specifically designed for indoor use and having a range of $0 \mathrm{mg}-21.0 \mathrm{gm}$ and plastic buckets. The balance, manufactured by Adam Equipment Company Limited, United Kingdom, is specially used to weigh light objects in the laboratory when a high degree of accuracy is expected. The rain gauge sensor attached to the environmental station had a capacity of $0.5 \mathrm{~mm}$ per tip and accuracy of one percent. The corrugated iron specimens were cut to small sizes of $100 \mathrm{~mm} \times 150 \mathrm{~mm}$ to conform to the requirements of ISO $9226[3,9]$. The small size is to minimize error of measurement and to facilitate easy handling during the experiment. Several small replicate specimens are known to give higher accuracy than a single large sheet [10]. The aerosol monitoring was done with an AMS950IS Intrinsically Safe Air-borne Particulate Monitor manufactured by CASELLA Limited, United Kingdom. Other facilities used in the experiment included 10-litre plastic buckets, 2-litre plastic bottles and a onemetre high stool.

Table 1. Site classification.

\begin{tabular}{cccc}
\hline Site & Enviroment & Location & Unique characteristics \\
\hline “M” QIT, Ibeno & Marine/industrial & $04^{\circ} 32^{\prime} \mathrm{N} / 07^{\circ} 55^{\prime} \mathrm{E}$ & a seaside oil facility with flare points that burn that burn all-year round \\
“N” NAOC Ebocha & industrial & $05^{\circ} 28^{\prime} \mathrm{N} / 06^{\circ} 41^{\prime} \mathrm{E}$ & a rural village with gas flare points that burn all-year round \\
“O” Forest Ekuri & Non-marine/rural & $04^{\circ} 31^{\prime} \mathrm{N} / 07^{\circ} 45^{\prime} \mathrm{E}$ & a clearing in the near Ekuri village \\
“P” Ogoja & Non-marine/urban & $06^{\circ} 399^{\prime} \mathrm{N} / 08^{\circ} 48^{\prime} \mathrm{E}$ & open field in a school compound \\
\hline
\end{tabular}




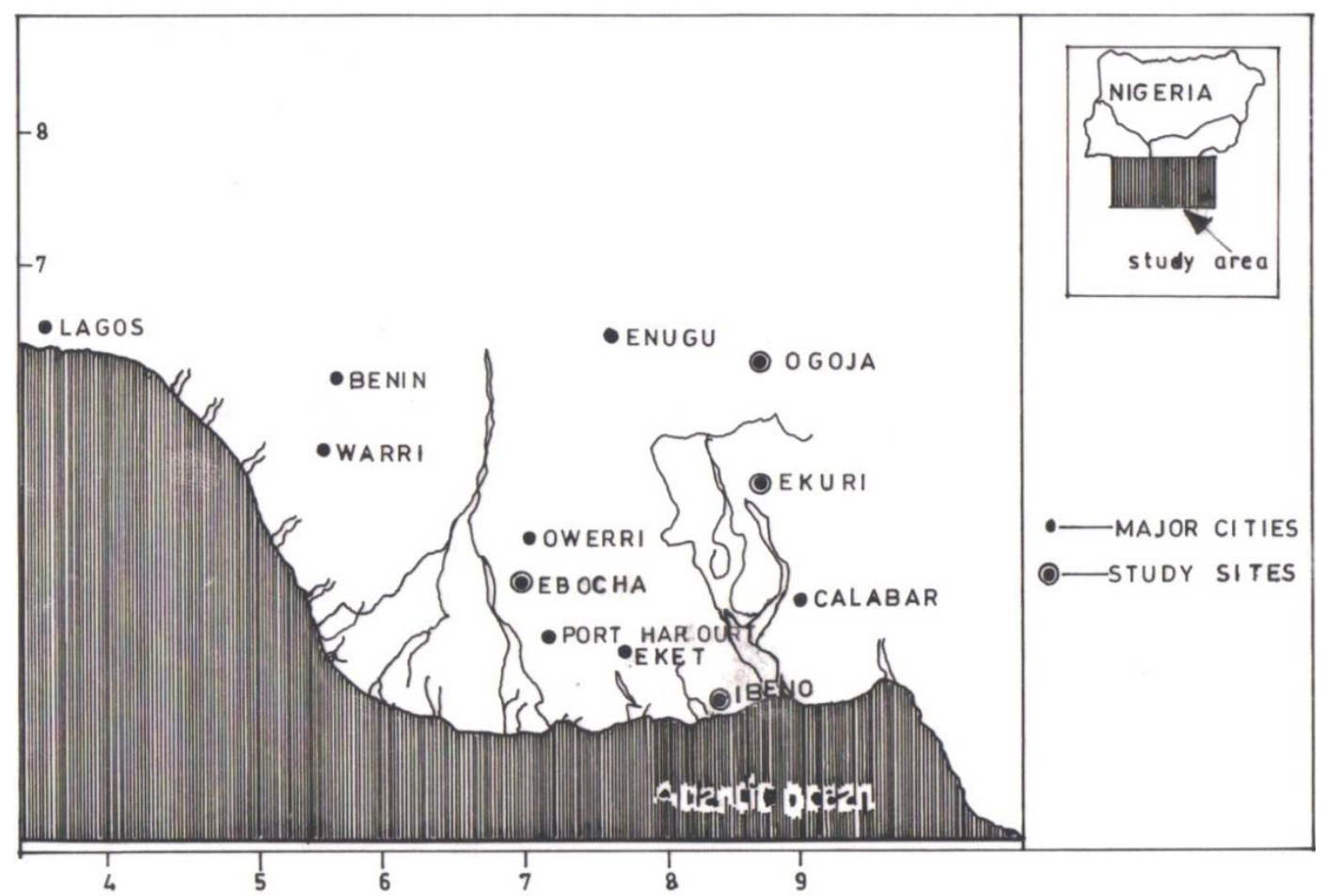

Figure 1. Map of Niger Delta of Nigeria with the study sites.

\subsection{Experimental Procedure}

The experiment involved the atmospheric exposure of the local commercial galvanized iron, as described previously, for 12 months. Periodic monitoring of the concentrations of particulate matter exuded as by-products of combustion at the flare chambers and the amount of rainfall was carried out within the same period. Sample specimens of $100 \mathrm{~mm} \times 150 \mathrm{~mm}$ were cut from a one millimetre thick sheet of the metal and cleaned by prickling to remove scales and other products, polished, degreased and weighed before exposure $[3,6,9,17-19]$. The samples were suspended on a rack with the aid of plastic strings tied to nails fixed onto the wooden frame and inclined at an angle of $22^{\circ}$, the average slope of roofs across the region [10]. The rack assembly was fixed on a wooden pole and raised to a height of $1.2 \mathrm{~m}$ to avoid rain splashes from the surrounding ground. The samples on each rack were properly labeled and were in quadruplicates. At the end of each exposure event, the samples were cleaned as before and re-weighed. The difference between a sample mass before and after exposure represented the mass loss. The mean of the replicates' mass losses in a rack represented the mass loss at that station. The environmental monitoring equipment with the high sensitive rain gauge sensor and the fine particulates (aerosol) monitor were placed close to each rack whenever those parameters were to be sampled. In all, there were a total of 12 stations distributed evenly across the four sites. Each rack was made to face the dominant prevailing wind direction and planted within a distance of $100 \mathrm{~m}$ from each other and from a flare stack in the case of sites "M", Ibeno and "N", Ebocha where gas is flared. Site, "P", Ogoja was in a school premises at the out sketch of the town and in the case of site "O", Ekuri, a clearing in the forest on elevated hill (near the village of Ekuri) and free from any tree canopy or shade was selected (see Table 1).

The rainfall and aerosol monitoring were done between the hours of 0600 and 1200 and the monthly means determined. The rain water samples for laboratory analysis (for $\mathrm{pH}$ determination) were collected on event basis, whenever it was convenient. However, this discrete collection was done within specific periods to reflect the seasonal variations of rainfall in the region. The water collection was done in March, the start of the rains, June, rains and November, the end of rains in the region. The rain water was collected with the aid of 10-litre plastic buckets placed on stools one metre high and in an open field. The collected water sample was put in 2-litre plastic bottles and firmly corked and taken to the laboratory for analysis.

\subsection{Statistical Treatment}

The data were analyzed by using SPSS 2007 statistical 
software package. The descriptive statistics of the data were first obtained (the means and standard deviations/ coefficients of variation). Multiple regression analysis and Pearson Product Moment correlation analysis were further performed on the data to determine the relative roles of the parameters as well as the correlation strength amongst them. Analysis of variance (ANOVA) was used to determine the means differences among the four study sites. The choice of these statistical tools is informed by the complex and multivariate nature of the atmospheric constituents [20].

\section{Results}

The average periodic readings of various parameters (mass loss, precipitation, aerosol concentration and $\mathrm{pH}$ ) are shown in Table 2. Figure 2 shows the comparative monthly rainfall across the sites. High rainfall was recorded between the months of May and December, except in September where there was less rainfall. In all, there was rainfall even in the

Table 2. Mean Readings of Mass Loss, Rainfall, Aerosol Concentration and $\mathrm{pH}$ of Rainwater

\begin{tabular}{cccccc}
\hline Site & $\begin{array}{c}\text { Station } \\
\text { Code }\end{array}$ & $\begin{array}{c}\text { Mean Mass } \\
\text { Loss }(\mathbf{m g})\end{array}$ & Rainfall $(\mathbf{m m})$ & $\begin{array}{c}\text { Aerosol } \\
\left(\boldsymbol{\mu g} / \mathbf{m}^{3}\right)\end{array}$ & $\mathbf{p H}$ \\
\hline “M” & $\mathrm{M}_{1}$ & 19.55 & 3382.80 & 17.30 & 5.20 \\
Ibeno & $\mathrm{M}_{2}$ & 24.80 & 3286.80 & 15.50 & 5.80 \\
& $\mathrm{M}_{3}$ & 38.38 & 4117.20 & 14.87 & 6.80 \\
& $\mathrm{Mean}$ & 27.58 & 3595.60 & 15.89 & 5.93 \\
“N” & $\mathrm{N}_{1}$ & 30.20 & 2437.20 & 18.27 & 5.10 \\
Ebocha & $\mathrm{N}_{2}$ & 41.90 & 3537.60 & 20.17 & 4.60 \\
& $\mathrm{~N}_{3}$ & 28.97 & 4237.20 & 14.95 & 6.00 \\
& $\mathrm{Mean}$ & 33.69 & 3404.00 & 17.80 & 5.23 \\
“O” & $\mathrm{O}_{1}$ & 0.25 & 666.96 & 7.82 & 6.80 \\
Ekuri & $\mathrm{O}_{2}$ & 7.46 & 1745.40 & 8.25 & 6.90 \\
& $\mathrm{O}_{3}$ & 18.24 & 3066.48 & 6.72 & 6.70 \\
& $\mathrm{Mean}_{3}$ & 8.65 & 1826.28 & 7.60 & 6.80 \\
“P” & $\mathrm{P}_{1}$ & 10.45 & 2045.00 & 16.20 & 6.10 \\
Ogoja & $\mathrm{P}_{2}$ & 19.50 & 778.80 & 11.80 & 5.90 \\
& $\mathrm{P}_{3}$ & 21.22 & 2101.20 & 9.47 & 6.30 \\
& $\mathrm{Mean}$ & 17.06 & 1641.67 & 12.49 & 6.10 \\
\hline
\end{tabular}

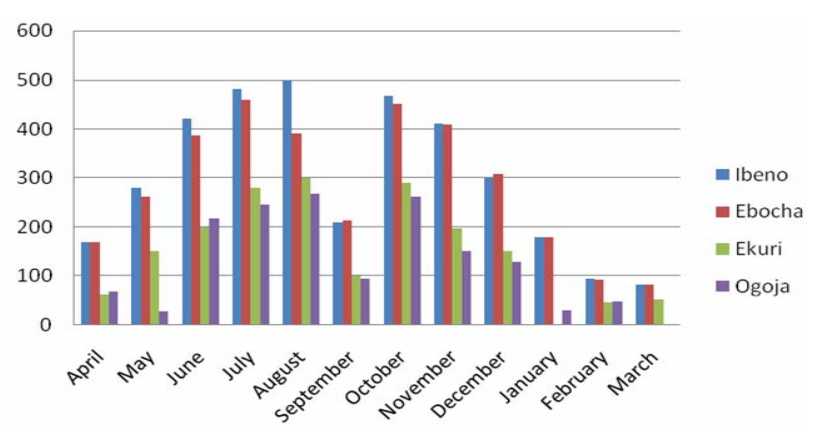

Figure 2. Monthly rainfall across the study sites. dry months of December to March. The sites also showed marked variation in rain distribution. The highest yearly rainfall amount was $4237.20 \mathrm{~mm}$ (recorded at station " $\mathrm{N}_{3}$ " at Ebocha site) while the least $(666.96 \mathrm{~mm})$ was at station " $\mathrm{O}_{1}$ ", at Ekuri, indicating a high coefficient of variation of $45.45 \%$. Aerosol concentration and $\mathrm{pH}$ parameters have low coefficient of variation of $33.41 \%$ and $12.41 \%$. The output result of the regression analysis shows coefficients of 26.349 (constant), 0.006 for variable $X_{1}$ (rainfall), 0.394 for $\mathrm{X}_{2}$ (aerosol concentration) and -4.282 for $\mathrm{X}_{3}(\mathrm{pH})$ of rainwater. The emergent regression model is as shown thus: $\mathrm{Y}_{\text {(mass loss) }}=26.349+0.006 \mathrm{X}_{1}+$ $0.394 \mathrm{X}_{2}-4.282 \mathrm{X}_{3}$.

$$
\mathrm{Y}_{(\text {mass loss) }}=26.349+0.006 \mathrm{X}_{1}+0.394 \mathrm{X}_{2}-4.282 \mathrm{X}_{3}
$$

The measure of significance is 0.045 within the probability of $<0.05$, and the coefficient of determination, $R^{2}$ is 0.678 . Computed correlation coefficients reveal rainfall as having the highest values of 0.647 (partial), 0.481 (part) followed by aerosols with corresponding values of 0.119 (partial) and 0.068 (part). The values for $\mathrm{pH}$ are -0.236 (partial) and -0.138 (part).

The result of analysis of variance indicates that there is a significant difference $(p<0.05)$ in mass loss between the sites. A Post Hoc Test (LSD) shows that there is a significant mean difference $(25.04 \mathrm{mg})$ between sites " $\mathrm{N}$ " (Ebocha) and "O" (Ekuri). Also, sites "M" (Ibeno) and "O" (Ekuri), and "N" (Ebocha) and "P" (Ogoja) showed significant mean differences of $18.93 \mathrm{mg}$ and $16.63 \mathrm{mg}$ respectively between them $(p<0.05)$. On the other hand the mean differences between sites "M" (Ibeno)/ "N" (Ebocha) (6.11 mg), “M" (Ibeno)/“P”(Ogoja) (10.52 mg) and "O"(Ekuri)/“P”(Ogoja) $(8.41 \mathrm{mg})$ indicated insignificant mean differences $(p>0.05)$.

\section{Discussions}

The resultant high coefficient of variation of the rainfall variable $(45.40 \%)$ suggests that there was a wide difference in distribution of this parameter across the sites. Also, the partial correlation coefficient of 0.647 for rainfall shows that the parameter contributed $64.7 \%$ to the corrosion problem. Ogoja (site "P"), the northernmost site (with mean annual rainfall of $1641.67 \mathrm{~mm}$ ) is at the southern margins of Nigerian savannah belt and is roughly $400 \mathrm{~km}$ away from the sea, hence the weak influence of the south west trade wind that drives rain from Atlantic Ocean hinterland. On the other hand, Ibeno (site "M"), with mean annual rainfall of $3595.6 \mathrm{~mm}$ is just by the bank of the ocean and close to the equator, with low cloud height and high frequency of rainfall and dews formation.

The result of the ANOVA and the subsequent Post Hoc (LSD) tests suggest that Ebocha was the most im- 
pact site, followed by Ibeno. The least impacted sites were Ekuri and Ogoja. Ekuri, the control station in the experiment, was relatively free from anthropogenic pollution as noticed at the two industrial sites of Ebocha and Ibeno. From the Post Hoc Test the mean mass loss difference between Ibeno and Ebocha $(6.11 \mathrm{mg})$ is insignificant $(p>0.05)$, indicating similarity in pollutant composition between them. Similarly, the mean difference between Ekuri and Ogoja $(8.4 \mathrm{mg})$ is insignificant $(p<$ 0.05 ). On the other hand, Ibeno and Ekuri showed the largest significant mean difference of $25.04 \mathrm{mg}(p<$ $0.05)$.

The lesser correlation (partial and part) values of aerosol of 0.119 and 0.068 and the corresponding negative values for $\mathrm{pH}$ of -0.236 and -0.138 could be understood. The heavy rainfall makes it difficult for particulates (aerosols) and aqueous acidic pollutants to remain suspended in the atmosphere of this heavily wet region for long, thus masking their influences in the evolving atmospheric corrosion chemistry. Moreover, only two sites (Ibeno and Ebocha) are within flare zones while the other two (Ogoja and Ekuri) are far away from crude oil exploitation activities (400 km and $200 \mathrm{~km}$ respectively). Coincidentally, the two aerosol-prone environments are also zones of heavy rainfall. Thus the diluting and scavenging effect of the rain reduces the apparent concentration of the atmospheric aerosol and hence $\mathrm{pH}[5,21]$ and thus giving a pseudo-impression of light aerosol concentration across all the sites. As explained, this does not absolve these parameters from contributing to the corrosion build up.

Corrosion in this region could be caused more by dew as the $\mathrm{pH}$ of dew is far more acidic than that noticeable in the rain water [5]. The high humidity in the region leads to high frequency of dew formation. The dew water-bubbles on the metallic roof surface act as micro electrolyte that helps to initiate and promote corrosion. The subsequent rainfall would then likely wash away the formed corrosion subtracts, thereby exposing the pitted surface to further corrosion attack. Precipitation, includeing dew formation, is enhanced by particulates (aerosols) and acidic droplets (products of gas flaring). These particles, most of which are hygroscopic, serve as nuclei for cloud droplets, thus accelerating condensation $[18,19]$. In all, the combined influence of all these parameters is highly significant $\left(R^{2}=0.678\right)$, suggesting that about $67.8 \%$ of the corrosion is attributed to these factors in combination.

Much of the gas flared in this region is methane, which in combination with a small proportion of other hydrocarbons such as ethane and propane, constitute about $90 \%$ of the total, and as such the temperature of the flares is expected to be between $1870^{\circ} \mathrm{C}$ and $3000^{\circ} \mathrm{C}$ and this figure is far above the $1204^{\circ} \mathrm{C}$ at which molecular nitrogen begins to oxidize [21]. Therefore, it is evident that nitrous oxides $\left(\mathrm{NO}_{\mathrm{x}}\right)$ would be abundant within the vicinity of the flare chambers [21]. This invariably leads to the formation of the highly reactive nitric acid which, in addition to other acidic hydrocarbon particles of poor combustion, would be visited on the metallic roofs as acid rain, thereby initiating and promoting the corrosion in the region.

\section{Conclusions}

This study has shown no doubt, that rainfall and gas flaring parameters have contributed significantly to the corrosion of galvanized iron roofs in the Niger Delta. While little or nothing could be done about the climate, the anthropogenic impact of gas flaring could be checked. The most obvious environmental solution is the discontinuation of gas flaring in the region. The choice of another roofing material with high resilience to corrosion attack is an attractive alternative provided it is affordable to the ordinary low-income citizen of the region. Therefore, architects and material scientists should research alternative ecologically benign and sustainable materials. The paper also recommends that more studies should be undertaken to verify the influence of dews in the corrosion of metals under such climates as seen in the Niger Delta. However, it is important to note that effect of gas flaring is not limited to material degradation; marine and terrestrial ecosystems are equally impacted besides the direct health effect often complained about. There is the need for research into alternative uses for the exuded gases even as it has an additional economic benefit.

\section{REFERENCES}

[1] A. K. Kuruvillo, "Life Prediction and Performance Assurance of Structural Materials in Corrosive Environments-A State-of-the-Art Report," Advanced Materials and Processes Technology Information Analysis Center, Falls Church, 1999.

[2] J. Guthrie, B. Battat and C. Grethlein, "Accelerated Corrosion Testing," AMPTIAC Quarterly, Vol. 6, No. 3, 2002, pp. 11-15.

[3] M. Natesan, S. Selvaraj, T. Manickam and Venkatachari, "Corrosion Behaviour of Metals and Alloys in MarineIndustrial Environment," Science and Technology of Advanced Materials, Vol. 9, No. 4, 2008, Article ID 045002. doi:10.1088/1468-6996/9/4/045002

[4] T. E. Graedel, "Effects of Emissions to the Atmosphere on Materials and Cultural Artifacts," In: V. Galvert, Ed., The Chemistry of the Atmosphere; Its Impact on Global Change, Blackwell, Oxford, 1994, pp. 42-65.

[5] E. Johansson and M. Linder, "The Influence of Environ- 
mental Acidification in the Atmospheric Corrosion of zinc," Proceedings of 12th International Corrosion Congress, Vol. 2, 1993, pp. 549-560.

[6] J. Tidblad, A. A. Mikhilov and V. Kucera, "Acid Deposition Effect on Metals in Sub-Tropical Countries: Data Compilation and Temperate Climate Comparison," SCI Report 2000:8E, Swedish Corrosion Institute, Stockholm, 2000.

[7] T. E. Graedel and E. Legraf, "Scenarios for Atmospheric Corrosion in the $21^{\text {st }}$ Century," Electrochemical Society, 2001, pp. 24-30.

[8] S. Syed, "Atmospheric Corrosion of Materials," Emirate Journal of Engineering Research, Vol. 11, No. 1, 2006, pp. 1-24.

[9] J. Tidblad, V. Kucera, F. Samie, S. N. Das, C. Bhamornsut, L. C. Peng, K. L. So, Z. Dawei, L. T. H. Lien, H. Schollenberger, C. V. Lungu and D. Simbi, "Exposure Programme on Atmospheric Corrosion Effects of Acidifying Pollutants in Tropical and Subtropical Climates," Water, Air and Soil Pollution Focus, Vol. 7, No. 1-3, 2007, pp. 241-247. doi:10.1007/s11267-006-9078-6

[10] A. E. Obia, "Environmental Impact of Atmospheric Pollutants on Galvanized Iron Sheets in the Niger Delta Region of Nigeria," Ph. D. Thesis, University of Calabar, Calabar, 2008.

[11] World Bank, "Defining an Environmental Strategy for Niger Delta (1)," World Bank Confidential Report, Washington DC, 1995.

[12] E. Uyigue and M. Agho, "Coping with Climate Change and Environmental Degradation in the Niger Delta of Southern Nigeria," Community Research and Development Centre, Benin City, 2007.

[13] I. J Ekpoh, and A. E. Obia, "The Role of Gas Flaring in the Rapid Corrosion of Zinc Roofs in the Niger Delta Re- gion of Nigeria," Environmentalist, Vol. 30, No. 4, 2010, pp. 347-352. doi.:10.1007/s10669-010-9292-7.

[14] R. O. Idris, "Impacts of Oil Spillage and Gas Flaring on the Population and Distribution of Birds in the Niger Delta region of Nigeria: A brief Interim Report Prepared for ABC Conservation Fund, United Kingdom,” 2010. www.africanbirdclub.org.

[15] Wikipedia, "Environmental Issues in the Niger Delta," 2010. http://en.wikipedia.org/wiki/sustainability/.

[16] D. O. Egbuna, "The Environmental Hazard of Nigerian Natural Gas," Proceedings of an International Seminar on the Petroleum Industry and the Nigerian Environment, Lagos, September 1987, pp. 346-351.

[17] M. Moniruzzaman and A. S. M. A. Haseeb, "Investigation into the Causes of Premature Corrosion of Pre-Fabricated Steel Factory Building," Journal of Mechanical Engineering, Vol. ME40, No. 2, 2009, pp. 90-94.

[18] L. Chotimongkol, C. Barmornsut,, R. Nkuntool, N. Kaevmonkol, S. Sulphonlai, E. Vitiat, I. Cole and A. Neufeld, "Corrosion Monitoring of Metallic Building and Infrastructural Metals in Thailand," Proceeding of Asian-Pacific Corrosion Control Conference, Ho Chi Minh City, Vol. 2, 1999, pp. 555-570.

[19] L. T. H. Lien, P. T. San and H. L Hong, "Results of Studying Atmospheric Corrosion in Vietnam 1995-2005," Science and Technology of Advanced Materials, Vol. 8, No. 7-8, 2007, pp. 552-558. doi:10.1016/j.stam.2007.08.011.

[20] E. B. Eze, "Statistics in Environmental Management," Diageg Nigeria Enterprises, Calabar, 2005.

[21] C. T. I. Odu, "Gas Flare Emissions and Their Effects on the Acidity of Rain Water in the Ebocha Area," University of Ibadan, Ibadan, 1994. 